clear oil. The analysis gave: $\mathrm{N}$, 10.5 ; calculated for $\mathrm{C}_{10} \mathrm{H}_{10} \mathrm{O}_{3} \mathrm{~N}_{2} \mathrm{~S}_{2}$, I0.37.

New Haven ConN., July I6, 1906.

\title{
THE CHLOR-HYDROCHLORIDES OF PINENE AND FIRPENE.
}

BY G. B. Frankforter and Francis C. Frary.

Received August 2, Igo6.

The Purification of Pinene and Firpene.-The pinene used in the preparation of the following compounds was obtained from the common white turpentine by distilling with steam, drying and redistilling until the boiling-point was constant at $156-157^{\circ}$. An analysis showed that the substance consisted entirely of hydrogen and carbon, and the physical properties corresponded with those of pure pinene.

The firpene used was obtained from the western fir by distilling the crude pitch with steam. The water-white terpene was dried and redistilled several times. Combustion gave numbers which corresponded with the formula $\mathrm{C}_{10} \mathrm{H}_{18}$. Molecular weight determinations also gave numbers which corresponded well with the above formula. Its odor, its specific gravity, its refractive index and its optical activity differed from the pure pinene. The chemical properties, likewise, differed from pinene.

The following is a comparison of the physical properties of the two substances:

\begin{tabular}{|c|c|c|}
\hline ng-point & $\begin{array}{l}\text { Pinene. } \\
156^{\circ}-157^{\circ}\end{array}$ & $\begin{array}{c}\text { Firpene. } \\
153^{\circ}-153.5^{\circ}\end{array}$ \\
\hline Sp. gr. at $20^{\circ}$.. & 0.8647 & 0.8598 \\
\hline Index of refraction at $20^{\circ} \ldots \ldots \ldots \ldots$ & 2.46336 & 1.47299 \\
\hline Optical activity $(\alpha)_{D} \ldots \ldots \ldots \ldots \ldots \ldots$ & 14.34 & -47.2 \\
\hline
\end{tabular}

Preparation of Pinene Hydrochloride.-The pinene hydrochloride prepared by the common method contains a considerable quantity of soluble oily and resinous matter from which it is separated with great difficulty. In fact, we were unable to find a satisfactory method for the separation of the hydrochloride from these oily and resinous substances. A new method therefore seemed important. After many trials, the following process was finally chosen as being entirely satisfactory. Pure pinene was mixed with about an equal volume of dry chloroform in a large roundbottomed flask, mixed thoroughly and cooled below $0^{\circ}$. Pure 
dry hydrochloric acid gas was passed into the liquid until it became saturated with the acid.

It was necessary to pass the gas into the pinene very slowly at first as considerable heat is generated. After saturation, an equal volume of water was added and the excess of acid removed by the addition of sodium bicarbonate. This mixture was immediately subjected to steam distillation. The chloroform which passed over first contained a considerable quantity of the hydrochloride; the greater part, however, remained in the flask after all the chloroform had been removed. Further steam distillation carried it over in to the condenser where it soliclified in comparatively pure form. The chloride still contained a very small quantity of a colorless oil. All the resinous matter, however, was completely removed. After most of the hydrochloride had distilled over, the oil began to appear. It is important that the solid chloride should be removed from the condenser before the oil begins to pass over as they readily mix and are difficult to separate from each other. It was found that the hydrochloride could be removed by cooling to $-30^{\circ}$, filtering off the crystals and drying between sheets of filter-paper. Two or three crystallizations of the chloride from alcohol gave a substance which melted at $\mathrm{I} 3 \mathrm{O}-\mathrm{I} 3 \mathrm{I}^{\circ}$, which is the melting-point of pure pinene hydrochloride as stated by Long. ${ }^{1}$ This method has been used in the preparation of all of the hydrochlorides and hydrobromides of both pinene and firpene and of the terpene from the Norway pine.

CHLOR-HYDROCHLORIDES OF PINENE AND FIRPENE.

Pinene Pentachlorhydrochloride, $\mathrm{C}_{10} \mathrm{H}_{13} \mathrm{Cl}_{5} \mathrm{HCl}$. - Several chlorine compounds have been prepared from pinene, the most important of which are nitrosyl-chloride ${ }^{2}$ pinene dichlorhydrochloride ${ }^{3}$ of questionable composition and trichloride of dipentene. These and a few other compounds have been described but owing to the difficulty experienced in purifying them, only the above-mentioned compounds have been studied. Most of these chlorides were made by difficult complex methods which have been tried by others and found to give a mixture of several compounds with such closely associated properties that separation seems to us

1 This Journal, 21, 637 .

2 Ibid. 9,554 ( 1887 ).

${ }^{3}$ J. Russ. Chem. Soc. 25,383 .

4 Anv. $270,196$. 
next to impossible. Hypochlorous acid has been mentioned in a number of experiments. This reagent gives impure oxychlorterpenes which could not be separated. In a single other case, Hesse $^{1}$ used chlorine in a carbon disulphide solution. Examination of this method showed that in each case the reaction was deep-seated and several compounds, often of oily nature, were formed, together with sulphur and sulphur compounds.

Many different methods were tried by others without satisfactory results. Hydrochloric acid with potassium permanganate was finally tried and found to give good results. The method adopted was as follows: A known weight of the terpene hydrochloride was dissolved in 5 times its weight of pure chloroform and an equal quantity of water added and stirred. An equal weight of potassium permanganate was added and hydrochloric acid (sp. gr. r.2) added cautiously. The flask was corked and allowed to stand for some time. Fresh additions of hydrochloric acid and permanganate were added from time to time. The process was continued for a week, taking care to keep an excess of chlorine in the solution. The chloroform was then separated from the water and a few drops of alcohol added to absorb the excess of chlorine. The chloroform solution was of a yellowish green color, due to the presence of free chlorine. After removing the chloroform by evaporation, the solid amorphous residue was crystallized from warm alcohol, dissolved in ether, clarified with bone-black and recrystallized several times from alcohol.

The crystallized substance resembled somewhat the original pinene hydrochloride in belonging to the isometric crystal system. The corrected melting-point, however, was I $73-174^{\circ}$.

These crystals were deliquescent in both ether and chloroform vapors. Evaporation of the ether and chloroform left an amorphous substance. The presence of alcohol, however, reproduced the crystals. Analyses of the pure substance gave the following numbers:

0.2250 gram substance gave 0.5619 gram $\mathrm{AgCl}$.

0.2044 gram substance gave 0.2586 gram $\mathrm{CO}_{2}$ and 0.0562 gram $\mathrm{H}_{2} \mathrm{O}$.

Calculated for $\mathrm{C}_{10} \mathrm{H}_{12} \mathrm{Cl}_{8}: \mathrm{C}, 34.74 ; \mathrm{H}, 3.5 \mathrm{I} ; \mathrm{Cl}, 6 \mathrm{I} .69$. Found : I. $\mathrm{Cl}, 6$ I.75; II. C, $34.50 ; \mathrm{H}, 3.05$.

1 Ann, 270, 196. 
An attempt to make the pentachloride directly from pinene instead of the hydrochloride by chlorinating with hydrochloric acid and potassium permanganate, failed. The result in every attempt was a heavy oily mass with distinctly aromatic odor. This oil readily decomposed in the air, changing to a brown mass.

From the fact that this compound can not be prepared without first converting the terpene into the hydrochloride, we have represented it as well as the other analogous chlorine compounds which follow as a hydrochloride.

Pinene Hexachlorhydrochloride, $\mathrm{C}_{10} \mathrm{H}_{10} \mathrm{Cl}_{6} \mathrm{HCl}$.-Pinene hydrochloride was dissolved in chloroform and treated with dry chlorine in bright sunlight. Chlorine was passed into the solution for eight hours. Upon evaporation a residue was left which resembled somewhat the pentachloride. It was purified by recrystallizing from alcohol several times or until the melting-point became constant at $218^{\circ}$. The chlorine determination gave results higher than the theoretical but near enough to indicate that the compound is a hepta compound, 66.5 I per cent. of chlorine being found. Calculated for $\mathrm{C}_{10} \mathrm{H}_{10} \mathrm{Cl}_{8} \mathrm{HCl}, 65.43$ per cent.

Pinene Nonachlorhydrochloride, $\mathrm{C}_{10} \mathrm{H}_{8} \mathrm{Cl}_{8} \mathrm{HCl}$. - In the preparation of pinene hexachlorhydrochloride, there was left in solution after the hexachlor compound had crystallized out of carbon tetrachloride, a sticky substance which refused to crystallize. This substance was dissolved in pure carbon tetrachloride and dry chlorine passed through the solution until it remained a bright yellow color after standing six hours in bright sunlight without the further addition of chlorine. Upon evaporation of the tetrachloride a waxy sticky mass remained, having about the consistency of "grained honey." No further reaction seemed to take place after standing several months. This waxy mass was then extracted with boiling 95 per cent. alcohol, when the oily part dissolved, leaving most of the crystals. By repeated extraction with large quantities of alcohol, the whole mass of crystals dissolved. Upon cooling the alcoholic solution, most of the substance crystallized out again. After recrystallization the substance had a melting-point of $263-264^{\circ}$ (uncor.). Further recrystallization failed to change the melting-point.

Analysis of this substance gave the following results: 
I. O.I950 gram substance gave $0.5655 \mathrm{gram} \mathrm{AgCl}$.

2. O. I9 10 gram substance gave 0.5579 gram $\mathrm{AgCl}$.

3. $0.158 \mathrm{I}$ gram substance gave 0.3473 gram $\mathrm{AgCl}$.

4. 0.1457 gram substance gave 0.3228 gram $\mathrm{AgCl}$.

Calculated for $\mathrm{C}_{10} \mathrm{H}_{7} \mathrm{Cl}_{9} \mathrm{HCl}: \mathrm{Cl}, 73.47$. Found: $\mathrm{Cl}, 7$ 1.69, 72.22, $72.14,72.76$.

It will be seen that the chlorine found is lower than the theoretical. It was at first thought that perhaps the substance was a mixture of nona- and decachlorhydrochloride. The constant melting-point, however, indicated a single substance. Finally, a molecular weight determination was made and the results obtained corresponded closely with the above theory.

The substance resembles the pentachlorhydrochlorice in its crystal form and properties but it is much less soluble in alcohol and has less odor. Alcoholic silver nitrate did not remove any of the chlorine, while several months' standing with excess of silver oxide removed only a very small part of the chlorine. Sodium methylate in absolute alcohol seemed to have no effect upon it. Neither boiling nitric acid (sp. gr. I.4) nor a boiling mixture of this with two parts sulphuric acid had any apparent effect upon it. It is more soluble in absolute alcohol than in 95 per cent. alcohol and is very soluble in benzene, ether, chloroform and carbon tetrachloride.

The Action of Bromine on the Hydrochloride.-It was found that bromine would not act readily upon the hydrochloride. The hydrochloride was exposed to the sunlight in the presence of bromine for a month, no change evidently having taken place during that time. By long treatment with hydrobromic acid in the presence of potassium permanganate and sulphuric acid, an aromatic oil was obtained. This oil proved to be a bromide but has not been obtained in pure enough state for analysis.

COMPOUNDS OF FIRPENE.

Firpene $\mathrm{H} y d$ rochloride, $\mathrm{C}_{10} \mathrm{H}_{10} \mathrm{HCl}$. - Firpene hydrochloride was made by the same method given for the preparation of pinene hydrochloride. After crystallizing several times from alcohol the substance had a melting-point of $130-131^{\circ}$, the same as pinene hydrochloride, but differing from the latter by being more volatile and more soluble in nearly all the common solvents and having a slightly different odor. From chloroform and carbon tetra- 
chloride, it is amorphous. Chlorine determinations gave the following:

I. 0.2760 gram substance gave 0.22723 gram of $\mathrm{AgCl}$.

2. 0.2704 gram substance gave $0.22143 \mathrm{gram}$ of $\mathrm{AgCl}$.

Calculated for $\mathrm{C}_{10} \mathrm{H}_{10} \mathrm{HCl}: \mathrm{Cl}, 20.55$. Found: $\mathrm{Cl}, 20.39$ and 20.25 .

Firpene Dichlorhydrochloride, $\mathrm{C}_{10} \mathrm{H}_{14} \mathrm{Cl}_{2} \mathrm{HCl}$. - Firpene hydrochloride differs widely from pinene hydrochloride in its chemical properties, especially when treated with chlorine. Pinene hydrochloride will not form a dichlorhydrochloride but forms with excess of chlorine the hexachlorhydrochloride. Firpene hydrochloride on the contrary readily forms a dichlorhydrochloride, but repeated attempts to make higher chlorides were unsuccessful, the dichloride being always formed. The dichloride proved to be less volatile and less soluble in alcohol than the hydrochloride and more soluble than the pinene pentachloride.

Analysis gave $44.2 \mathrm{I}$ per cent. $\mathrm{Cl}$; calculated for $\mathrm{C}_{10} \mathrm{H}_{16} \mathrm{Cl}_{2} \mathrm{HCl}$, 44.04 .

Firpene Hydrobromide, $\mathrm{C}_{10} \mathrm{H}_{18} \mathrm{HBr}$.- - Firpene forms a well crysta1lized hydrobromide which differs entirely from the pinene hydrobromide. The method of preparation was the same as that used in the preparation of the hydrochloride. Thoroughly dried hydrobromic acid gas was passed into a chloroform solution of firpene. The crystalline substance was purified by recrystallizing from alcohol. The pure substance had a melting-point of $102^{\circ}$. The hydrobromide of pinene melts at $90^{\circ}$. The crystals seem to have a feathery form, are readily pressed into a gummy mass and are very volatile. It has a pronounced odor of camphor. It is soluble in nearly all the common organic solvents.

Bromine determinations gave $36.9^{8}$ per cent. $\mathrm{Br}$; calculated for $\mathrm{C}_{10} \mathrm{H}_{10} \mathrm{HBr}, 36.86$ per cent.

Behavior of Pinene and Firpene with Nitrosyl Chloride.-One of the most characteristic and easily prepared compounds of pinene is the nitrosylchloride. The method given by Wallach ${ }^{1}$ was followed to the letter with both pinene and firpene. The former gave without difficulty a fine crystalline substance while the latter gave no crystalline compound even after repeated trials. A small quantity of an oily substance obtained from firpene may have possibly been a nitrosochlor compound. In fact, this reaction seems to be a characteristic of firpene as well as of pinene.

1 Ann. 253, 25I; 245, 25I. 
The chlorine compounds made thus far are oils, no matter how much or how little chlorine has entered the compound. These oils are difficult to purify inasmuch as all of them decompose before the boiling-point is reached. We have had several compounds in hand but have as yet been unable to purify them. On the contrary both firpene and pinene when first converted into the hydrochlorides, form crystalline compounds of chlorine, the meltingpoint rising with the increase of chlorine until the decachlor compound is reached. Substitution products from these various chlorides are now in preparation.

University of Minnesoth,

MIKNeapolis, MINN.

\section{THE PITCH AND THE TERPENES OF THE NORWAY PINE AND THE DOUGLAS FIR.}

BY G. B. FRANEFORTER.

Received August 2, Ig06.

PRELIMINARY.

IT HAS been known for several years that the Norway pine and the Douglas fir are rich in the terpenes and resin. During a few days in the spring, the Norway pine seems almost as rich in pitch and turpentine as its southern sister species but the conditions are such that "boxing" as practised in the south is out of the question. A series of "boxing" experiments resulted in collecting a considerable quantity of pitch for chemical examination and incidentally proved the impracticability of this method in the north. Although boxing does not seem practicable in the north and west, so far as $I$ have been able to determine, the reason seems to be largely due to climatic conditions so that if the pitch and turpentine of the north and west are to be utilized, other methods than the common method of the south must be employed.

At the present time, nothing has been done by the lumbering industries either in the north or west toward utilizing the large amount of waste pitchy material. As a result, enormous quantities of wood, too rich in pitch to be of any value to the lumbering industries are burned or thrown aside as worthless. The enormous profits in lumber have made it unnecessary for lumbering industries to look to any of the by-products in order to earn large dividends on capital invested. As a natural consequence 